\title{
Numerical Simulation on goaf with different vertical distances in high-drainage roadways
}

\author{
Rili Yang ${ }^{1, *}$, Jianbin $\mathrm{Cui}^{2}$, Fengfeng Yang ${ }^{1}$, Jufeng Zhang ${ }^{1}$, Lan $\mathrm{Yu}^{1}$ \\ ${ }^{1}$ School of Energy Engineering, Long-Dong University, Qing'yang, Gan'Su, 745000 \\ ${ }^{2}$ School of Mathematics and Statistics, Long-Dong University, Qing'yang, Gan'Su, 745000
}

\begin{abstract}
High drainage roadway horizon parameters not only influence goaf drainage effect, but also have effect on the air leakage field and spontaneous combustion three zones' distribution in the goaf. Combined with mine fire-prevention and goaf spontaneous combustion three zones recognition, it was put forward to stimulate the distribution law of goaf air leakage field and spontaneous combustion three zones with fluid mechanics software FLUENT. The results showed that the width of goaf oxidization and heat accumulation zone increased with high drainage roadway vertically. Through stimulation study, it supplies a certain method to reasonablely optimizatate high drainage roadway vertical parameters, which to a great extent ensures mine safety production, fire and gas prevention.
\end{abstract}

\section{Introductions}

The gas drainage technology of high-drainage roadway is a commonly used gas drainage method, through arranging roadways among the goaf coal seam, adjacent layers and surrounding rocks, which is intended to reduce gas concentration in the return airway lane and prevent the gas concentration in the upper corner from exceeding the limit. The technology has the advantages of long drainage time, large influence radius of drainage, and significant drainage effect. However, from the perspective of fire prevention and extinguishment, the gas drainage in highdrainage lanes increases the risk of spontaneous combustion of coal left in the goaf ${ }^{[1-2]}$. According to the knowledge about ventilation and fire extinguishing, with the air leakage and the possibility of spontaneous combustion of the remaining coal, the goaf can be divided into three zones ${ }^{[3-4]}$ : heat dissipation zone, spontaneous combustion zone and suffocation zone, of which spontaneous combustion zone is also called oxidation temperature rise zone, It is an oxidation heating zone $e^{[5]}$, where easily suffers from fire risk.

The Spatial horizon parameters of the high-drainage roadway studied in this paper mainly refer to the arrangement of the high-drainage roadway at a vertical distance from the coal seam roof, which is called the vertical distance parameter. Different vertical parameters of the high-drainage roadway have different degrees of influence on the flow field of the goaf and the distribution of the spontaneous combustion zone.

\section{Coal mine general situation}

The workface, which is the third mining face arranged along the coal seam in the east wing of the mining area. The coal mining method is fully mechanized top coal caving. The whole formation of the working face presents a monoclinic structure. It is inclined to the northwest, and the slope of the coal seam is not large, between $1^{\circ}$ and $7.5^{\circ}$. The coal seam is a spontaneously ignited coal seam, and coal dust has an explosion risk, and the ignition period is extremely short, only 3-5 months, and the shortest 24 days. It is a type I spontaneously ignited coal seam. The mine is currently using comprehensive fire prevention measures supplemented by yellow mud grouting and three-phase foam injection, supplemented by nitrogen injection in the mined-out area, vapor fog suppression, sealing and plugging, and monitoring and forecasting. The influence of factors were ignored such as roof lithology and working face advancement speed, only taken the changes in the oxidation heating zone caused by the air leakage flow field.

\section{Physical model and numerical simulation parameter settings}

\subsection{Establishment of physical model}

The coal seam inclination angle of the working face is between $1.0^{\circ}$ and $7.5^{\circ}$, which belongs to near-horizontal

\footnotetext{
*Corresponding author: 446048772@qq.com
} 
coal seam. In order to facilitate the establishment of a physical model, it was taken as horizontal during the simulation (inclination angle is $0^{\circ}$ ). The goaf area in the model is a multi-porous Porous zone, while the intake air lane, return air lane, working face and high extraction lane were all fluid zones. The fluid space was divided into free spaces turbulent part of the working face and the porous medium space seepage part of the goaf. The details were shown in Table 1.

Table 1. Physical model geometry size table

\begin{tabular}{|c|c|c|c|}
\hline & length & Width & height \\
\hline Inlet and return airway lane & 30 & 4 & 4 \\
\hline Workface & 180 & 5 & 4 \\
\hline Goaf & 200 & 180 & 80 \\
\hline High drainage roadway & & 2 & 2 \\
\hline
\end{tabular}

\subsection{Discretization method and boundary condition setting}

The grid is the geometric expression of the CFD model and the carrier of simulation and analysis. The basic model is created and generated by the Fluent preprocessor Gambit. Combined with the actual air supply volume of the working face and the needs of model calculation, the air inlet lane was set as the velocity inlet boundary, the air volume is $720 \mathrm{~m}^{3} / \mathrm{min}\left(12 \mathrm{~m}^{3} / \mathrm{s}\right)$, the speed is $0.75 \mathrm{~m} / \mathrm{s}$; the return air lane and high drainage roadways were all free exit boundaries (outflow), and the proportions were outlet. $1=0.75$ and outlet. $2=0.25$. The permeability of porous media space was customized according to the law of falling and breaking of overlying strata at different positions in the goaf.

\section{Numerical simulation experiment and result analysis}

According to the relevant theory of the mine surrounding rock and the actual situation of the mine, the simulation experiment set four vertical distances, respectively $\mathrm{H}_{1}=15 \mathrm{~m}, \mathrm{H}_{2}=30 \mathrm{~m}, \mathrm{H}_{3}=45 \mathrm{~m}, \mathrm{H}_{4}=60 \mathrm{~m}$. During the course of analyzing the distribution law of spontaneous combustion in the goaf, the influence of the average thickness of the floating coal, the particle size of the falling and broken rock and the average velocity of the air leakage flow on the width of the oxidation heating zone were considered, so a separate goaf was selected.

When the horizontal distance parameter of the highdrainage roadway layout remained unchanged, and the vertical distance parameter $\mathrm{H}$ was respectively: $15 \mathrm{~m}, 30 \mathrm{~m}$, $45 \mathrm{~m}$, and $60 \mathrm{~m}$, the distribution law of the three-zone spontaneous combustion zone on the $2 \mathrm{~m}$ horizon was shown in Figure 1 (a), (b), (c), (d). Among them, the red area in the image indicated the heat dissipation zone, the air leakage speed was greater than $0.004 \mathrm{~m} / \mathrm{s}$, the blue area indicates the suffocation zone, and the air leakage speed was less than $0.0016 \mathrm{~m} / \mathrm{s}$, the area between the red and the blue area is oxidation heating zone. In addition, the upper boundary of the image was the side of the inlet air lane, and the lower boundary was the side of the return air lane.

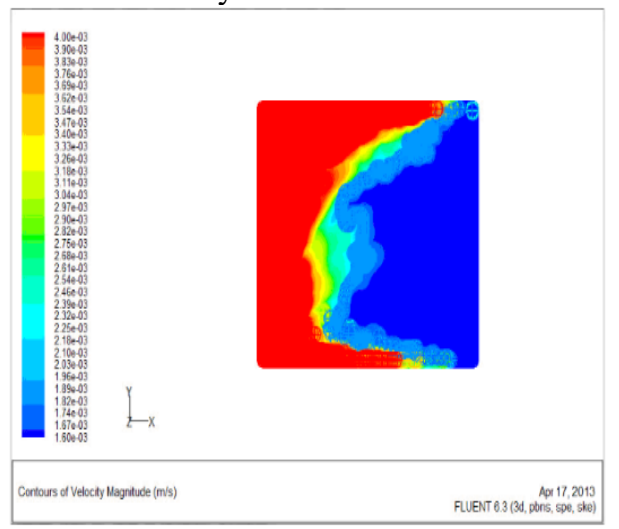

(a) $\mathbf{H} 15+\mathbf{L 3 0}$

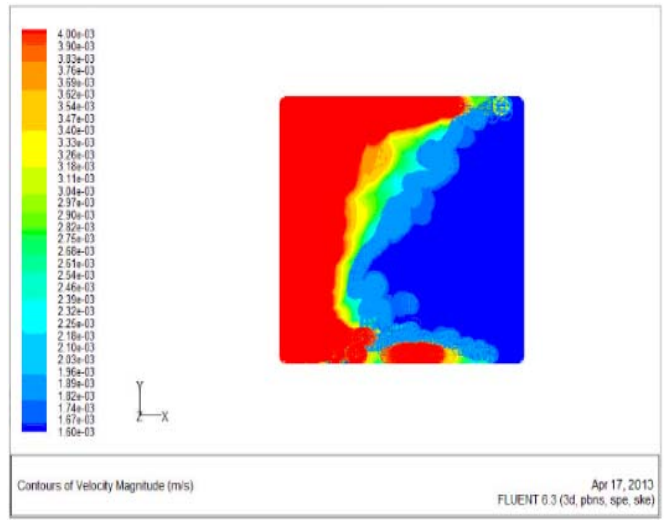

(b) $\mathbf{H 3 0}+\mathbf{L} 30$
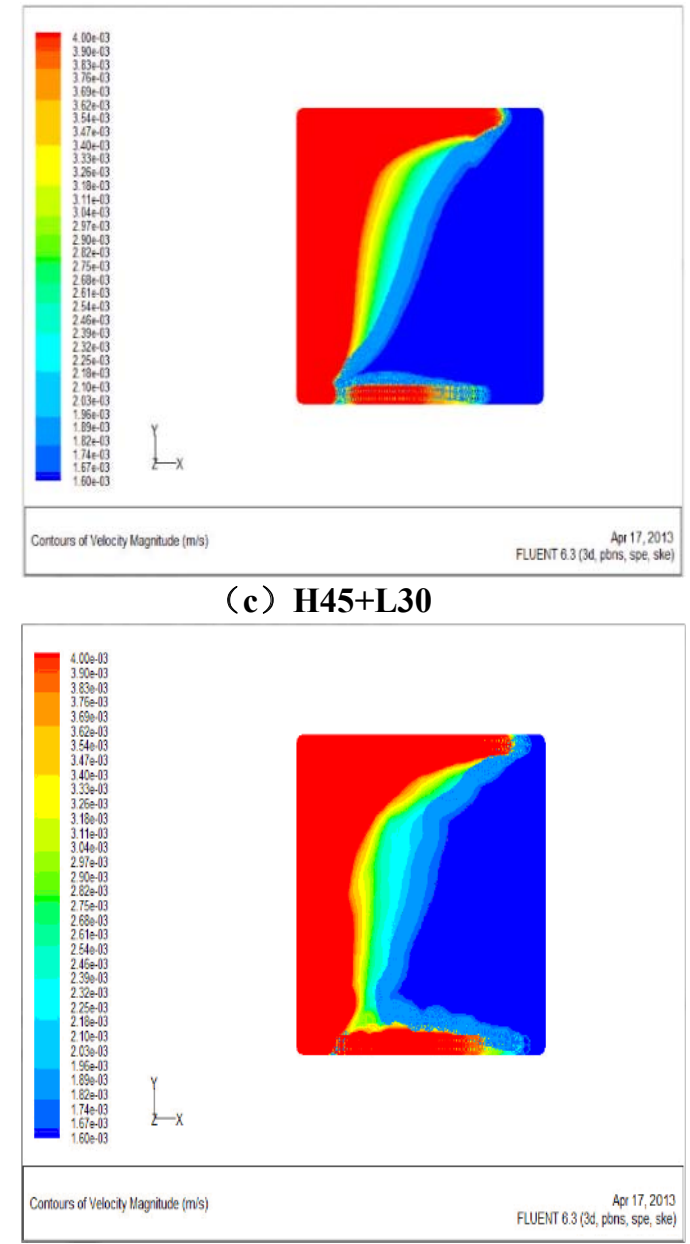


\section{(d) $\mathrm{H60}+\mathrm{L30}$}

Fig.1 Distribution laws of oxidation heating zone in goaf with different vertical distance parameters

It could be seen from Fig. 1 (a), (b), (c) and (d) that when the vertical parameter of the high pumping lane changed, the width of the spontaneous combustion zone in the goaf all changed significantly. On the side of the air inlet lane, because part of the air in the working face flow into the goaf with the air leakage form, the heat radiation zone of the goaf near the side of the air inlet extended to the deeper area of the goaf; The air leakage flow into the goaf mainly flows through the upper corner, and the remaining part of the air leakage flow was mainly distributed in the goaf in the middle of the working face, so the above area dissipated heat The area of the belt gradually was narrow; near the side of the return air lane, due to the influence of some high extraction roadways extending into the goaf for gas drainage activities, the range of the heat radiation zone of the goaf side of the return air lane also extended to the deep goaf region. The figure showed the width of the oxidation heating zone was a narrow middle width at both ends from top to bottom, what is more, the oxidation heating zone widths were smaller near the boundary of the inlet lane and the boundary of the return lane, but the width in the goaf near the middle of the working face is larger, which were caused with air leakage transported and migrated from the middle of the working face to the deep goaf area.

Because the widths of the oxidation heating zone were different on the upper and lower sides of the goaf, and the shape presented irregular, and it was difficult to measure its range by calculating the area. Therefore, a trend with the working face was defined on the $2 \mathrm{~m}$ horizon The line was in the same direction and run through the goaf. This line was located in the middle of the working face and perpendicular to the working face. It was denoted as $y=90$, and the oxidation temperature rise zone was represented by the width on the straight line when the speed range was $0.0016-0.004 \mathrm{~m} / \mathrm{s}$. width. After the calculation results of the simulation experiment were output, the velocity distribution on the straight-line $\mathrm{y}=90$ was processed and analyzed, the details were shown in Table 2.

Table 2. Variation of the width of the oxidation heating zone in the goaf under different vertical distance parameters

\begin{tabular}{|c|c|c|c|}
\hline \multicolumn{2}{|c|}{$\begin{array}{c}\text { Horizontal } \\
\text { distance } \\
\mathbf{L}=\mathbf{3 0 m}\end{array}$} & $\begin{array}{c}\text { Oxidation } \\
\text { temperature } \\
\text { zone distance }\end{array}$ & $\begin{array}{c}\text { Oxidation } \\
\text { temperature width }\end{array}$ \\
\hline \multirow{3}{*}{$\begin{array}{c}\text { Vertical } \\
\text { distance }\end{array}$} & 15 & $46 \sim 95$ & 49 \\
\cline { 2 - 4 } $\boldsymbol{H}$ & 30 & $45 \sim 100$ & 55 \\
\cline { 2 - 4 } & 45 & $41 \sim 103$ & 62 \\
\cline { 2 - 4 } & 60 & $33 \sim 107$ & 74 \\
\hline
\end{tabular}

Combined with the coal mine production parameters and procession, it was calculated that the longest distance of the oxidation heating zone in the goaf is $120 \mathrm{~m}$. It could be seen form the Table 2, when the high-drainage roadway was pumped under different vertical distance parameters, the distance of the oxidation heating zone in the goaf was nearly within $120 \mathrm{~m}$, but when the vertical parameter $\mathrm{H}$ was $15 \mathrm{~m}$, the oxidation zone was the farthest
The distance was $95 \mathrm{~m}$, and the maximum distance at which the oxidation temperature rise zone occurred when the vertical distance parameter $\mathrm{H}$ was $60 \mathrm{~m}$ the value reached $107 \mathrm{~m}$.

In the compaction area, the greater the vertical distance parameter of the high-drainage roadway was, the closer to the $120 \mathrm{~m}$ range. The variation trend of the width of the oxidation heating zone in the goaf under different vertical distance parameters were shown in Fig. 2.

\section{variation tread on the width of the oxidation heating zone}

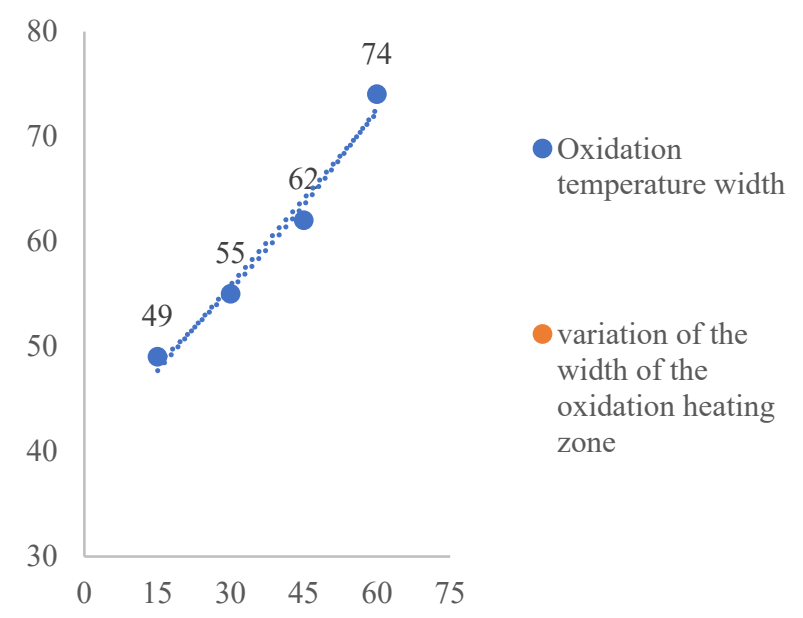

Fig. 2 Variation trend of oxidation and heating zone in goaf under different vertical distance parameters

It can be seen from Figure 2, when the vertical distance parameter $\mathrm{H}$ exceeds $45 \mathrm{~m}$, the increasing speed of the width of the oxidation heating zone increases significantly. Combined with Table 2 and Figure 2, the larger the vertical distance of the high pumping lane was, the more likely the oxidation heating zone would appear in the goaf, and the larger the width, that would be detrimental to the prevention of spontaneous combustion of coal in the goaf. What is more, it was more appropriate to take the smaller value of the vertical distance parameter of the high pumping lane. On the other hand, the highdrainage roadway should be arranged as far as possible in the range of the fissure zone to better realize the drainage of the goaf gas and the average height of the fissure zone in the working face is about $19-25 \mathrm{~m}$. At the same time, it was more conducive to the drainage of higher concentration gas in the goaf. Therefore, considering the factors of gas drainage in high-drainage roadway and fire prevention and extinguishment in goaf area, the best vertical distance parameter $\mathrm{H}$ determined in this paper was $30 \mathrm{~m}$.

\section{Conclusions}

(1) The width of the oxidation heating zone in the goaf area increases with the vertical parameter increasement in the high-drainage roadway. When the high-drainage lane is arranged in the range of the fissure zone, the greater the vertical distance of the high-drainage lane is, the more beneficial it is to the drainage of higher concentration gas in the goaf. Therefore, the optimal vertical distance 
parameter $\mathrm{H}$ of high-drainage roadway in the workface was finally determined to be $30 \mathrm{~m}$.

(2) The width of the oxidized heating zone depends on various factors such as roof lithology, working face propulsion speed, air leakage intensity, etc. Therefore, in the actual production process of the mine, the space for high pumping lanes should be continuously and reasonably optimized according to specific conditions Strata parameters, by changing or controlling the distribution of the air leakage flow field in the goaf.

\section{References}

1. T. Chu. Effect of Gas Drainage Induced by Spontaneous Combustion of Floating Coal in High Level Roadway Journal of Mining \& Safety Engineering, 29, 3 (2012)

2. J. Zheng. Study on the effect of air leakage in goaf on coal spontaneous combustion characteristic. XUST, 4 (2018)

3. Y. Zhao, Modeling of Flow Field and Partition of Spontaneous Combustion Danger Zone in Gob of Fully Mechanize. Safety in Coal Mines, 26, 6 (2011)

4. T. Chu. Numerical simulation analysis and practice of air flow field in goaf based on FLUENT. Journal of Henan Polytechnic University,29, 3 (2010)

5. J. Wang. Numerical Simulation of Different Gas Drainage Methods and Spontaneous Combustion Reasonable Balance in Goaf[J]. Journal of Safety Science and Technology, 36, 8 (2015) 